\title{
Improving the diagnosis and treatment of osteoporosis using a senior-friendly peer-led community education and mentoring model: a randomized controlled trial
}

\author{
This article was published in the following Dove Press journal: \\ Clinical Interventions in Aging \\ 16 May 2017 \\ Number of times this article has been viewed
}

\author{
Marita Kloseck ${ }^{1,2}$ \\ Deborah A Fitzsimmons 1,3,4 \\ Mark Speechley ${ }^{5}$ \\ Marie Y Savundranayagam' \\ Richard G Crilly',2 \\ 'Sam Katz Community Health and \\ Aging Research Unit, ${ }^{2}$ Division \\ of Geriatric Medicine, Western \\ University, London, ON, Canada; \\ ${ }^{3}$ School of Nursing and Allied Health, \\ Liverpool John Moores University, \\ Liverpool, ${ }^{4}$ School of Health and \\ Related Research, The University of \\ Sheffield, Sheffield, UK; ${ }^{5}$ Department \\ of Epidemiology and Biostatistics, \\ Western University, London, \\ ON, Canada
}

Correspondence: Marita Kloseck Sam Katz Community Health and Aging Research Unit, Faculty of Health Sciences, Arthur and Sonia Labatt Health Sciences Bldg, Room HSB 218 , Western University, London N6A 5B9, ON, Canada

Tel $+151966|211|$ ext 81230

Fax +I 5198502432 (shared)

Emailmkloseck@uwo.ca

\begin{abstract}
Background: This randomized controlled trial (RCT) evaluated a 6-month peer-led community education and mentorship program to improve the diagnosis and management of
\end{abstract} osteoporosis.

Methods: Ten seniors (74-90 years of age) were trained to become peer educators and mentors and deliver the intervention. In the subsequent RCT, 105 seniors (mean age $=80.5 \pm 6.9 ; 89 \%$ female) were randomly assigned to the peer-led education and mentorship program $(n=53)$ or control group $(n=52)$. Knowledge was assessed at baseline and 6 months. Success was defined as discussing osteoporosis risk with their family physician, obtaining a bone mineral density assessment, and returning to review their risk profile and receive advice and/or treatment.

Results: Knowledge of osteoporosis did not change significantly. There was no difference in knowledge change between the two groups (mean difference $=1.3,95 \%$ confidence interval $[\mathrm{CI}]$ of difference -0.76 to 3.36 ). More participants in the intervention group achieved a successful outcome (odds ratio $0.16,95 \%$ CI $0.06-0.42, P<0.001$ ).

Conclusion: Peer-led education and mentorship can promote positive health behavior in seniors. This model was effective for improving osteoporosis risk assessment, diagnosis, and treatment in a community setting.

Keywords: prevention, seniors, mentor, bone mineral density, capacity building, community knowledge translation

\section{Background}

The sequelae resulting from osteoporosis and osteoporotic fractures are significant and include functional impairment, ${ }^{1}$ institutionalization, ${ }^{2}$ and death. ${ }^{3}$ Despite the adverse outcomes, osteoporosis is largely underdiagnosed, with as few as $13 \%-25 \%$ of patients who experience a fragility fracture being investigated for osteoporosis by bone mineral density (BMD) assessment. ${ }^{4,5}$ Similarly, the management of osteoporosis is less than optimal, with those at high risk for fractures often remaining untreated. ${ }^{6-8}$ It is a challenge to improve the management of osteoporosis since, in the absence of an osteoporotic fracture, osteoporosis is symptomless and is dependent on risk assessment and screening for diagnosis. Successful risk screening not only depends on educating physicians but also relies on increasing public awareness of osteoporosis.

Self-management approaches to prevention and management of health conditions have been lauded as effective ways to improve health outcomes in adults and to reduce health care costs. ${ }^{9-11}$ Although self-management may be an effective strategy for younger (c)
hereby accept the Terms. Non-commercial uses of the work are permitted without any further permission from Dove Medical Press Limited, provided the work is properly attributed. For permission for commercial use of this work, please see paragraphs 4.2 and 5 of our Terms (https://www.dovepress.com/terms.php). 
age groups, it poses a challenge for seniors in advanced age who have multiple problems and reduced physical and mental capacity. Well-documented barriers include a large number of care recommendations, ${ }^{12}$ limited knowledge of medical conditions, ${ }^{13}$ cultural and communication factors and transportation issues, ${ }^{14}$ poor recall, ${ }^{15}$ and comorbidity and compounding effects of conditions. ${ }^{16}$ It has been suggested that self-help models of community development, in which some of the responsibility for health care planning and provision is placed not just in the hands of individuals but also on the community as a whole, may provide the greatest benefit. ${ }^{17,18}$ In particular, building community capacity using a peer support model (neighbors helping neighbors) may expand the potential pool of health and supportive services within a local setting. ${ }^{19,20}$ In the context of seniors, younger-old age groups may assist in supporting the oldest-old and friends and neighbors helping each other may extend the reach of the health system and assist the frail elderly to successfully age in place. ${ }^{19-21}$ The use of knowledgeable and skilled senior volunteers trained to educate their peers on health-related topics, although not new, is gaining popularity and support as an effective method of health promotion. ${ }^{22-24}$

This paper reports results from a pragmatic randomized controlled trial (RCT) of a participatory community development approach that actively engaged seniors in providing peer-led osteoporosis education and mentoring within a naturally occurring retirement community (NORC) in Ontario, Canada. Findings are reported in accordance with the Consolidated Standards of Reporting Trials (CONSORT) checklist for the reporting of pragmatic trials. ${ }^{25}$

\section{Study context}

This study consisted of two phases: 1) the recruitment and training of 10 osteoporosis peer educators and mentors to deliver the intervention and 2) an RCT to test the efficacy of the peer-led community osteoporosis education and mentoring program. Participants were recruited from a NORC in a major urban center in Ontario. This community consists of 12 privately owned apartment buildings housing over 2,500 seniors (mean age $=79$, standard deviation $[\mathrm{SD}]=9.53$ ) and 64 local businesses housed in a public mall adjacent to the apartment buildings. A previous survey showed that $54 \%$ of the population in this community were $>80$ years of age.

\section{Training of peer educators/mentors to deliver the intervention}

A town hall meeting was held to inform the community of the osteoporosis study, the need for peer educators and mentors, and the role that they would have to perform. Community members interested in the project were invited to establish contact. No specific inclusion or exclusion criteria were applied. After providing informed consent, 10 participants, all female, aged from 74 to 90 years, committed to becoming peer educators and mentors and entered Phase I of the study. All 10 peer educators/mentors participated in the education program presented over a 2-week period, after which four withdrew (two due to health issues, one due to family obligations, and one due to time constraints). The education program for peer educators/mentors consisted of five osteoporosis education modules presented at the level of a lay person and delivered by local experts. A detailed description of the education modules, including objectives, curriculum, and instructors, is provided in Table 1. Each education session was 1 hour in length followed by a question and answer period.

In addition, peer educators/mentors attended an education session focused on enhancing public presentation skills. This presentation was delivered by the project coordinator and focused on 1) confidently speaking in front of audiences, 2) effectively eliciting audience interest, participation, and feedback, 3) beginning your presentation, 4) delivering your presentation (encouraging audience involvement, keys to developing good listening skills, speaker's nonverbal communication, how to handle difficult situations), 5) concluding your presentation, and 6) key attributes of a senior-friendly presentation. Consistent with principles of community capacity building, once trained these peer educators/mentors formed the Community Osteoporosis Advisory Committee. Peer educators/mentors, as a group, took the information they were provided within the five training modules and, with the help of the research team, synthesized and repackaged the information in a way they felt comfortable presenting. This was an iterative process between the peer educators/mentors and the research team that took place over the course of 2 weeks. Once peer educators/mentors were comfortable, the repackaged material was presented to the local osteoporosis experts to check for clarity and accuracy.

\section{The intervention}

For the RCT, the intervention involved a 2-hour education program delivered to small groups of participants by pairs of peer educators/mentors (for mutual support), using the educational materials they had developed. The first hour consisted of the peer-led osteoporosis education program where participants learned about osteoporosis, assessment, and treatment using the repackaged presentation of the five education modules. During the second hour, each peer 


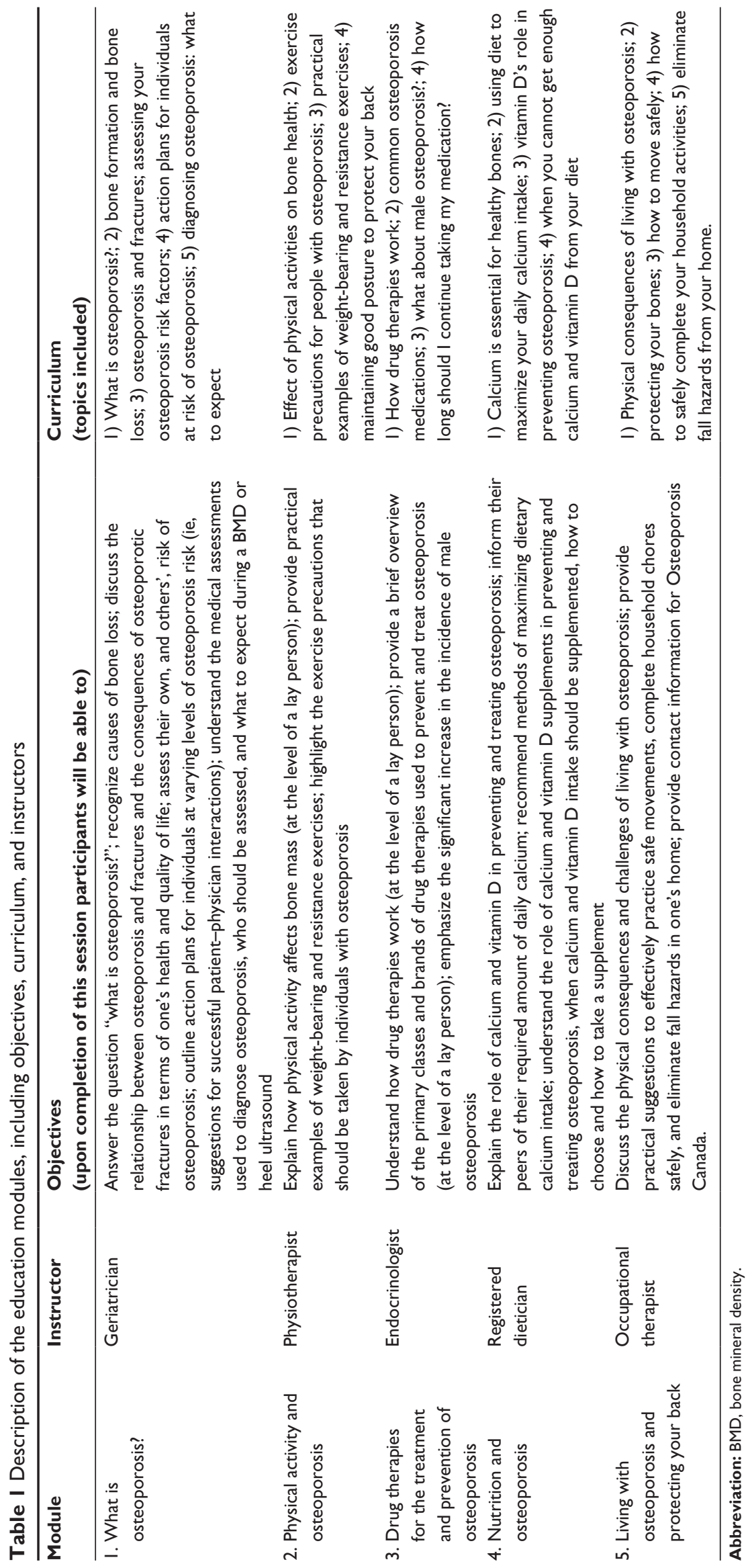


educator/mentor was assigned up to nine participants to mentor. A risk assessment tool and action plan was designed to facilitate participants' discussions with their family physician (Figure 1). Peer educators/mentors worked one-on-one with their assigned participants to complete Part 1 of the tool (Figure 1) that included questions about past fractures, family history, drug use, and other factors known to increase risk of fractures. These risk factors were consistent with those outlined in the Canadian guidelines for the diagnosis and management of osteoporosis at the time of the study. ${ }^{26}$

Participants who had not had a BMD assessment done were requested to arrange an appointment with their family physician to request a BMD assessment. If, and when, this was obtained, and for those who already had a BMD assessment done but had not discussed results with their physician, a further appointment with their physician was advised to discuss the results.

During this visit, the physician was presented with Part 1 of the risk assessment and action plan tool (Figure 1) and was requested to complete Part 2. If the physician did not complete the risk tool and therefore did not provide the BMD result, the participant subsequently requested, via a release of information form, that the BMD result be faxed to one of the study physicians (RC). Each participant was tutored by their peer educator/mentor on the questions to ask their family physician, the information they should obtain, and to discuss appropriate management based on the information recorded on their risk assessment tool. The objective of the RCT was to test whether a participatory community development approach that actively engages seniors in providing peer-led osteoporosis education and mentoring could be used to improve the diagnosis and management of osteoporosis.

\section{Methods}

The study reported in this paper involved a pragmatic two-arm RCT conducted over a 2-year period from 2007 to 2009.

To ensure the study was as inclusive as possible, individuals were eligible to participate if they were $\geq 65$ years of age and lived within the NORC. Recruitment was confined to English speaking individuals. Potential participants were recruited by the peer educators/mentors using a number of strategies: word-of-mouth, notices posted in the public shopping mall and in the mail and laundry rooms of the 12 apartment buildings, a mall table display, and advertising on the internal community television channel. Potential participants identified by the peer educators/mentors were provided with an information package containing a letter of information about the study, a consent form, and a baseline demographic, risk and knowledge questionnaire (further details below). The peer educators/mentors provided potential participants with assistance in completing the forms if it was required. Informed consent was obtained from each participant. The study coordinator reviewed all completed consent forms and questionnaires for completeness prior to enrolling and randomizing the participants to the peer-led education program $(n=53)$ or to a control group $(n=52)$. Participants were randomized using the sequentially numbered, opaque sealed envelope method of randomization and allocation concealment. ${ }^{27}$ Three education sessions for 14 participants and one final session for up to 12 participants were planned. To maintain balanced allocation throughout recruitment, a batch approach was used. One batch of 28 envelopes (14 for the intervention and 14 for the control) was created by the study coordinator and used for the first 28 participants enrolled. A second batch of 28 envelopes was used for the second wave of participants recruited, a third batch of 28 for the third wave, and fourth batch of 22 for the final wave (recognizing that one of the allocation envelopes would not be required for a sample of 105 participants). It was not possible to blind the involved parties to their allocation due to the nature of the intervention and the study design.

The knowledge questionnaire (provided as Supplementary material) included multiple choice and true or false questions related to the five key content areas to be covered by the education modules: what is osteoporosis; physical activity and bone health; drug therapies for the prevention and treatment of osteoporosis; nutrition and bone health; and living with osteoporosis and protecting your bones. The risk questionnaire was derived by the research team based on a review of published material. The knowledge questionnaire was developed by the research team based on the information being delivered in the education modules and subsequently reviewed for face validity by the osteoporosis content experts. The knowledge questionnaire is assumed to have face and content validity as the questionnaire and the correct responses are based on up-to-date expert knowledge reflecting recent guidelines and clinician expertise. The knowledge questionnaire was self-administered and scored by the research coordinator. Test scores were calculated by summing the correct number of responses minus the incorrect responses. To ensure that all scores were positive values, 25 was added to each score for a maximum possible score of 44 points. Participants allocated to the control group received usual care, that is, the care which would normally be provided without this intervention, while the intervention group attended a peer-led 
Osteoporosis "Points of Opportumity" Program

TAKE THIS FORM WITH YOU TO YOUR DOCTOR APPOINTMENTS

\section{PEER ADVISORS TO FILL IN WITH PARTICIPANTS}

According to the 2002 Clinical Practice Guidelines for the diagnosis \& treatment of osteoporosis in Canada, all individuals over age 65 should have a bone mineral density test done.

(CMAJ 2002; 167 (10 suppl): S1-S34).

I I am over 65

I have had a Bone Mineral Density (BMD) test in the last 5 years: $\square$ Yes $\square$ No

In addition, I have the following osteoporosis risk factors:

$\square$ Prior spine fracture

$\square$ Mother had osteoporosis \&/or fractures

P Prior wrist fracture

a Father had osteoporosis \&/or fractures

$\square$ Prior upper arm (humerus) fracture

$\square$ Prior hip fracture

I have lost inches in height.

$\square$ Prior rib fracture

\section{ACTION:}

Arrange an appointment with your doctor to schedule a BMD

$\square$ Arrange an appointment with your doctor to obtain and discuss the results of your BMD

\section{TAKE TO YOUR DOCTOR \& FIIL IN WITH YOUR DOCTOR}

If no BMD in the last 5 years, schedule a BMD with your doctor. BMD scheduled: $\square$ Yes $\square$ No If $\mathrm{BMD}$ in the last 5 years, or after the above scheduled $\mathrm{BMD}$ has been completed:

What is my bone mineral density and what should I be doing?

Total Hip t-score: Spine t-score:

On the basis of my BMD results and other osteoporosis risk factors...

$\square$ I am at high risk of fracture

$\square$ I am NOT at high risk of fracture

What, if any, treatment should I be on?

$\square$ No prescription medication

$\checkmark$ The following prescription medication

What, if any, changes are required to my diet?

Should I take any supplements? a No $\square$ Yes (please list dosage)

Calcium:

Vitamin D :

What, if any, changes are required to my lifestyle?

Should I ever have a BMD done again? If so, when? years

(C) Sam Katz Community Health and Aging Research Unit

Figure I Risk assessment and action plan tool. 
osteoporosis education session followed by a 6-month personalized peer mentoring period which involved risk assessment, encouraging participants to visit their family physician, and encouraging compliance with physician recommendations. Following completion of the intervention, all trial participants in both intervention and control groups completed a second knowledge questionnaire.

\section{Data collection}

The planned sources of data collection were:

1. Participant submitted data: demographic, risk, and knowledge information were provided by all participants upon recruitment to the study.

Given the tightly-knit composition of this community, potential contamination of the control group was considered to be a significant risk. To determine whether information from the study had an impact upon the control group participants, this cohort was asked to complete a questionnaire at the end of the study to determine whether their behavior or knowledge had changed during the course of the study by assessing whether they had sought out their own information about osteoporosis and BMD testing from their family or friends, had started taking calcium or vitamin D supplements, had started exercising, or had spoken to their friends or neighbors about osteoporosis.

2. Peer educator/mentor collected data: the peer educator/ mentor provided their mentees with carbonless duplicate forms (Figure 1) asking participants to confirm their age, whether they had undertaken a BMD assessment in the past 5 years, and whether they had any of eight osteoporosis risk factors prior to the participant scheduling an appointment with their physician. Following the appointment and BMD assessment, participants were instructed to complete the second half of the duplicate form with their doctor. In their next meeting, the peer educator/mentor reviewed the BMD scores; whether or not the participant was at high risk of fracture; what, if any, treatment the participant was recommended by their physician; what, if any, changes to the participants diet had been recommended by their physician; whether calcium or vitamin D supplements had been recommended, and at what dosage; what, if any, lifestyle changes had been recommended; and whether a BMD assessment should be undertaken again in the future, and if so, when. Top copies of the duplicate form were handed back to the participant, and the lower copy was retained by the peer advisor and returned to the study coordinator.

On completing their intervention, the peer educator/ mentor also asked members of the intervention group to complete a second self-administered risk and knowledge information questionnaire.

\section{Sample size}

The initial RCT sample size calculation was based on achieving a significant improvement in the proportion of participants obtaining a BMD test, reviewing the results and their fracture risk profile with their family physician, and obtaining advice on treatment, if necessary. It was assumed that $\sim 30 \%$ would have had a BMD assessment done and have had appropriate follow-up at the start of the study and $40 \%$ of the control group may have achieved this by the end of the study, with an increase in the intervention group to about $75 \%$. Without any idea of what to expect for the composite outcome, this seemed both a feasible and clinically meaningful expectation. Using the Kelsey method, the effect size would be 0.725 with a total of 32 participants in each group to have $80 \%$ power at the $5 \%$ level of significance. Using the Fleiss method with continuity correction gives a required sample size of 36 per group to have $80 \%$ power at the $5 \%$ level of significance. Given the often frail nature of older subjects, and the potential for loss to follow-up for various reasons in people of this age, the overall recruitment target was increased to 100 . On review of the first cohort recruited, the recruitment target was revised to 105 participants as further protection against potential loss to follow-up and to ensure adequate power of the study.

Targeted recruitment by the peer educators/mentors ensured that all potential participants met the eligibility criteria, and recruitment was completed within a 6-month period.

\section{Follow-up}

Peer educators/mentors conducted formal follow-up mentoring sessions with intervention group participants monthly and more frequently informally as required. This was face-to-face or by telephone and aimed to encourage compliance with medication and lifestyle recommendations and to problem solve any barriers to compliance. Data were collected on an ongoing basis, as participants reached the goals. There were no specific time points beyond the 6-month termination time, as each participant's trajectory was different. Follow-up with the control group took place at the 6-month point. 


\section{Outcome measures}

Two outcome measures were identified and analyzed:

1. At the 6-month follow-up, the proportion of participants making a change in behavior related to their osteoporosis risk (obtaining a BMD assessment; returning to their family physician to review their risk profile and to obtain BMD results; and receiving treatment recommendations including calcium, vitamin D, and osteoporosis medication). For this study, appropriateness of the recommendation is not reported as the focus was on completion of the process and not to evaluate the knowledge base of the physicians. All components had to be met to achieve what was a composite outcome. Each participant could have been at different points in the outcome achievement at the start of the study. For example, a participant could have had a BMD done already but have had no follow-up with their family physician. The BMD had to have been done within the previous 2 years. All three of the composite outcomes had to be achieved to meet the endpoint. Participants already on osteoporosis medication were not specifically excluded on the basis that treatment did not necessarily mean that the other outcomes (such as BMD and fracture risk assessment) had been completed.

2. The improvement in participants' knowledge related to osteoporosis, including physical activity, drug therapies for the prevention and treatment of osteoporosis and nutrition.

\section{Analysis}

The between-groups difference in the proportion of participants making a change in behavior related to their osteoporosis risk was analyzed using the odds ratio and $95 \%$ confidence interval (CI). The between-group difference in knowledge change score was analyzed using an independent group $t$-test and $95 \% \mathrm{CI}$ of the difference score. McNemar's chi-square was used to analyze the change from baseline to follow-up in the proportion of the treatment group with adequate vitamin D intake. Study outcomes were analyzed on a per protocol basis. All analyses were conducted using OpenEpi 3.03a (www.openepi.com).

\section{Ethics}

Ethical approval was obtained from The University of Western Ontario Research Ethics Board for Health Sciences Research Involving Human Subjects, organized and operating according to the Tri-Council Policy Statement on the Ethical Conduct of Research Involving Humans and the Health Canada International Conference on Harmonization Good Clinical Practices Consolidated Guidelines (reference 12835E).

\section{Results \\ Recruitment}

The CONSORT ${ }^{25}$ flow chart for the trial is shown in Figure 2. In all, 105 participants were recruited, enrolled, and randomized within the study period.

The mean age of participants was 80.5 years $(\mathrm{SD}=6.9)$ and the majority (88.6\%) were female. Characteristics of the intervention and control groups are presented in Table 2 . The groups were well-balanced on several factors including age, gender, medication, and vitamin/mineral use, although the control group had more fractures than the intervention group and had already had more BMD tests performed. Surprisingly, $61 \%$ of participants had already had a BMD assessment performed but of these, only $22 \%$ knew what the result was and had discussed the results with their family physician.

Of the 105 participants, nine subjects from each group were lost to follow-up or chose not to complete the intervention (Figure 2). From the control group, two subjects declined to participate post-survey. Additionally, follow-up was incomplete for five participants in the control group and three in the intervention group. Three participants moved out of the community, one from the control and two from the intervention group. Within the intervention group, four participants withdrew from the study, one as a result of a fractured hip. One participant in the control group died prior to completing the follow-up.

\section{Achievement of outcomes Outcome I: change in osteoporosis behavior}

Compared with $30(73 \%)$ of the intervention group, only $13(30 \%)$ of the control group achieved a successful outcome (defined as obtaining a BMD assessment; returning to their family physician to review their risk profile and to obtain BMD results; receiving treatment recommendations) with regard to their osteoporosis behavior $\left(\chi^{2}[1]=10.84\right.$, $P<0.001$ ) (Table 3).

There was an increase in the number of the intervention group taking adequate vitamin D (800 IU/day) as defined by the Osteoporosis Canada Guidelines. ${ }^{26}$ The dose was checked by the peer educator/mentor reviewing the actual medication being consumed. Table 4 shows the change in adequacy of vitamin D intake in the intervention group. There was an improvement in the number of subjects taking an adequate 


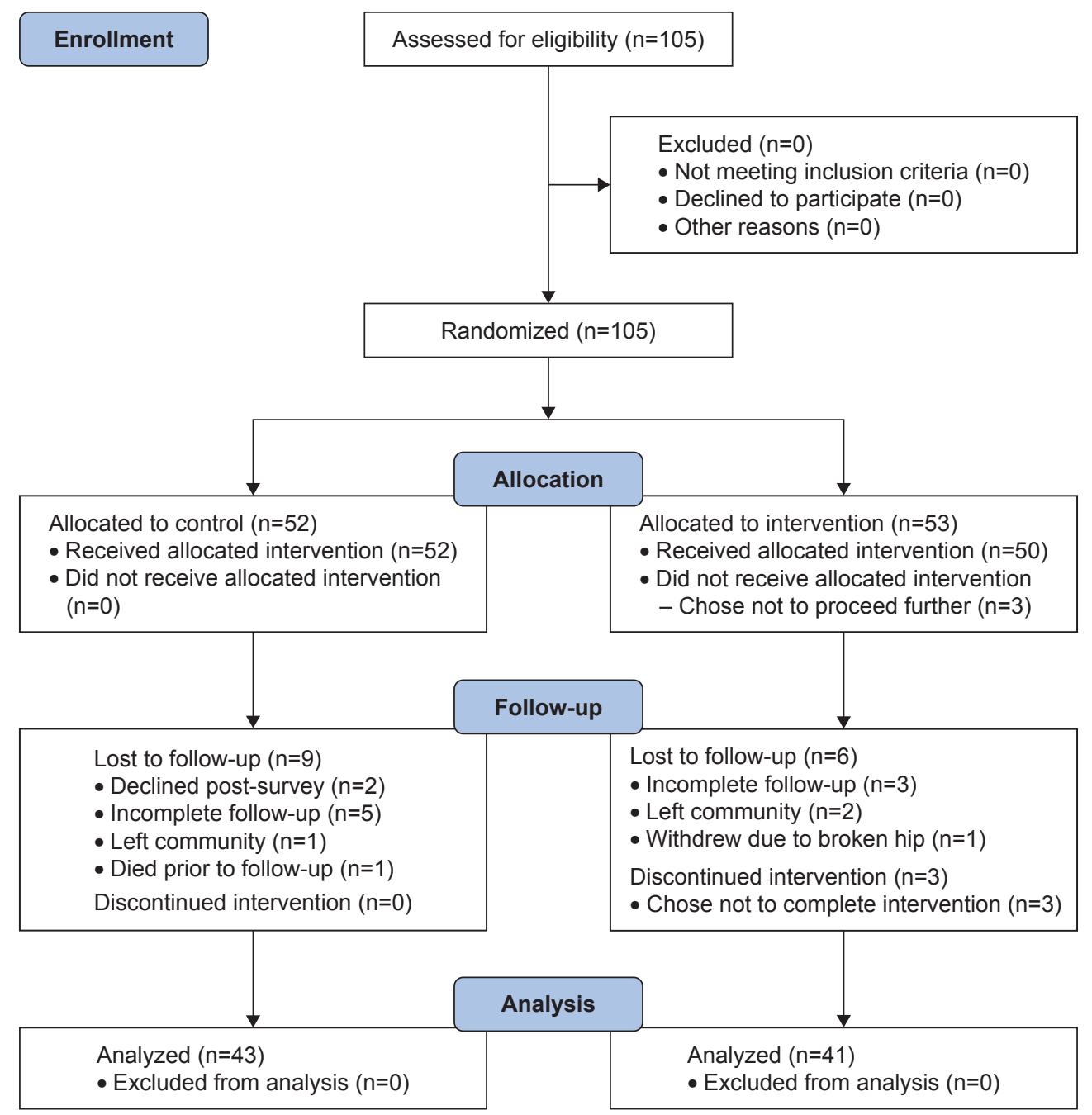

Figure 2 Consolidated Standards of Reporting Trials 2010 flow diagram.

dose of vitamin D (at least $800 \mathrm{IU} /$ day) from $24.4 \%$ to $46.3 \%$ at follow-up (McNemar's chi-square $P=0.02$ ). As the same level of certainty could not be assured for the control group, a similar analysis is not possible. However, there was a change in the behavior of the control group in that $31(73 \%)$ reported starting taking vitamin D supplements although the dosage could not be verified.

\section{Outcome 2: change in osteoporosis knowledge}

There was minimal improvement in knowledge in the intervention group (Table 3 ) and a minimal decline in the control group at the end of the 6-month intervention for a net betweengroup change of 1.3 points $(95 \% \mathrm{CI}$ of difference -0.76 to 3.36). This difference was not statistically significant.

\section{Discussion}

In this study, providing peer-led instruction, support, and guidance had a beneficial effect. Peer mentoring was successful in increasing the participant's willingness to approach the family physician to review their risk and treatment. It may be that the provision of the "cue" card (risk assessment tool) containing the relevant information, rather than expecting the patient to remember the salient information when face-to-face with the family doctor, made the appointment discussion both easier and more productive.

There was no statistically significant change in the participants' knowledge of osteoporosis prevention and management suggesting that change in knowledge was not the driving force behind the change in behavior. This observation raises doubts about the feasibility of using an awareness or educational model to change behavior and it does question the value of such an approach alone in the attempt to improve self-management of chronic conditions. Although the self-management model has gained widespread popularity, numerous limitations with this approach, particularly for frailer, older individuals, have 
Table 2 Baseline characteristics of participants

\begin{tabular}{|c|c|c|}
\hline Variables & $\begin{array}{l}\text { Intervention } \\
\text { group }(n=53)\end{array}$ & $\begin{array}{l}\text { Control } \\
\text { group }(n=52)\end{array}$ \\
\hline \multicolumn{3}{|l|}{ Sociodemographic variables } \\
\hline Female n (\%) & $47(88.7)$ & $46(88.5)$ \\
\hline Mean age in years (SD) & $81(6.9)$ & $80(7.0)$ \\
\hline Marital status n (\% married) & II (20.8) & $14(26.9)$ \\
\hline $\begin{array}{l}\text { Level of education } n \\
\text { (\% postsecondary) }\end{array}$ & $19(35.8)$ & $21(40.4)$ \\
\hline \multicolumn{3}{|l|}{ Risk assessment $\mathrm{n}$ (\% yes) } \\
\hline Previous fractures & $16(30.2)$ & $23(44.2)$ \\
\hline Spine & $2(3.8)$ & $3(5.8)$ \\
\hline Wrist & $8(13.2)$ & $15(28.8)$ \\
\hline Upper arm & $3(5.7)$ & $5(9.6)$ \\
\hline Hip & $3(5.7)$ & $2(3.8)$ \\
\hline Pelvis & $3(5.7)$ & $3(5.8)$ \\
\hline $\operatorname{Rib}(s)$ & $6(11.3)$ & $5(9.6)$ \\
\hline Maternal hip fracture & $6(11.3)$ & $4(7.7)$ \\
\hline Has become shorter with age & $32(60.4)$ & $39(75.0)$ \\
\hline Has fallen in the past year & $23(43.4)$ & $18(34.6)$ \\
\hline Has ever had a BMD completed & $28(52.8)$ & $36(69.2)$ \\
\hline Takes calcium supplements & $35(66.0)$ & $36(69.2)$ \\
\hline Takes vitamin D supplements & $36(67.9)$ & $35(67.3)$ \\
\hline Takes a multivitamin pill & $25(47.2)$ & $28(53.8)$ \\
\hline \multicolumn{3}{|l|}{ Prescription medication $\mathrm{n}$ (\% yes) } \\
\hline Osteoporosis medication use* & $13(26.4)$ & $14(28.8)$ \\
\hline Fosamax (alendronate) & $3(5.7)$ & $8(15.4)$ \\
\hline Actonel (risedronate) & $6(11.3)$ & $5(9.6)$ \\
\hline Didrocal (etidronate/calcium) & $3(5.7)$ & I (1.9) \\
\hline Evista (raloxifene) & I (I.9) & $\mathrm{I}(1.9)$ \\
\hline Miacalcin nasal spray (calcitonin) & $0(0.0)$ & $0(0.0)$ \\
\hline Estrogen or HRT & $2(3.8)$ & I (1.9) \\
\hline
\end{tabular}

Note: *Some participants were on $>$ I medication.

Abbreviations: SD, standard deviation; BMD, bone mineral density; HRT, hormone replacement therapy.

been identified. ${ }^{11,28-30}$ In particular, the short-term focus of current education programs and the difficulty in maintaining positive change after program completion when supportive resources are no longer available have been identified as major shortcomings. ${ }^{28}$ This approach, using peer educators and mentors, does however present some challenges as the pool of volunteers needs replenishment given the age, and sometimes the level of frailty, of senior peer leaders.
Green and Kreuter's ${ }^{31}$ model of health promotion outlines enabling factors (conditions and resources that allow or enable behavior change) and reinforcing factors (those that cue, remind, or reinforce behavior change), which are critical to facilitating changes in health-related behaviors. In this intervention, the peer mentorship component along with the risk assessment and action form served as the enabling and reinforcing factors that improved participants' behaviors targeted at osteoporosis assessment, prevention, and management. It is well-documented in the literature that education programs for health professionals that incorporate enabling and reinforcing factors are more effective in creating behavior change than those only aimed at disseminating information and increasing knowledge. ${ }^{32-34}$ It is also possible that providing the family physician with the information, as well as a summary of the risk factors highlighted in the guidelines, facilitated their response.

Pragmatic trials, undertaken in real-world settings, strive to provide evidence on the effectiveness of interventions within usual care settings to make their findings more generalizable. The development and undertaking of these trials is recognized to be more complex, and the 2008 extension of the CONSORT guidelines ${ }^{25}$ addresses the consistent reporting of many of the issues associated with pragmatic trials. However, it would seem that there are additional issues to consider when conducting a trial within a community setting. It is for these reasons that it could be argued that community-based trials provide an inferior level of evidence. If researchers are aware of the risks associated with conducting community-based trials, and if identified risks are appropriately addressed, these studies can provide high-quality evidence. For example, a recently published pragmatic pilot study ${ }^{35}$ on telehealth interventions in the UK identified problems with obtaining and maintaining care pathway fidelity. This issue was addressed by clinician education, clear messaging regarding the need to adhere to protocol, and vigilant analysis of care delivery to ensure that protocols were followed.

Table 3 Change in osteoporosis behavior and knowledge

\begin{tabular}{|c|c|c|c|c|c|}
\hline Variables & $\begin{array}{l}\text { Intervention } \\
\text { group }(n=4 I)\end{array}$ & $\begin{array}{l}\text { Control } \\
\text { group }(n=43)\end{array}$ & $\begin{array}{l}\text { Odds ratio } \\
(95 \% \mathrm{CI})\end{array}$ & $\begin{array}{l}\text { Mean difference }{ }^{* * *} \\
(95 \% \mathrm{CI})\end{array}$ & $P$-value \\
\hline Frequency of successful outcome* (outcome I) n (\% yes) & $30(73)$ & $13(30)$ & $0.16(0.06-0.42)$ & & $<0.001$ \\
\hline \multicolumn{6}{|l|}{ Knowledge test (outcome 2) mean points** (SD) } \\
\hline Baseline & $30.9(5.3)$ & $31.9(4.0)$ & & & \\
\hline 6-month follow-up & $31.8(4.7)$ & $31.1(4.7)$ & & & \\
\hline Knowledge change score ${ }^{* * * *}$ & $0.3(4.7)$ & $-1.0(4.8)$ & & I.3 (-0.76 to 3.36$)$ & 0.21 \\
\hline
\end{tabular}

Notes: *Defined as obtaining a BMD assessment; returning to their family physician to review their risk profile and to obtain BMD results; receiving treatment recommendations. **Test scores were calculated by summing correct responses minus the incorrect responses and adding 25 ; maximum total score $=44$. $* * * T w o-s a m p l e$ independent $t$-test of difference in knowledge change scores; $t_{82 \mathrm{df}}=1.25$. $* * * *$ The baseline score is for all participants whereas the change score represents the participants who completed both tests.

Abbreviations: SD, standard deviation; BMD, bone mineral density; $\mathrm{Cl}$, confidence interval. 
Table 4 Adequacy of vitamin $D$ intake in the intervention group

\begin{tabular}{llll}
\hline & \multicolumn{2}{l}{ Follow-up } & \\
\cline { 2 - 3 } & Adequate & Inadequate/none & $\mathbf{n}$ \\
\hline Baseline & & 3 & \\
Adequate & 7 & 19 & 10 \\
Inadequate/none & 12 & 22 & 31 \\
$\mathrm{n}$ & 19 & 41 \\
\hline
\end{tabular}

Note: There was an increase in the number of participants taking adequate vitamin $D$ from 10/4I (24.4\%) to 19/4I (46.3\%) (McNemar's chi-square $P=0.02$ ).

For the current study, the selection of a NORC as the location ensured an adequate number of participants and peer mentors could be recruited perhaps more readily than in a standard community. However, the nature of this community posed a challenge to the researchers as a result of the proximity and frequent interaction between participants; so risk of contamination of the control group could hardly be avoided. While the risk of contamination of the control group could be seen as a methodological weakness, in reality it may have been an asset, as the control group also changed their behavior with regard to osteoporosis. This demonstrated the value of the informal networking and communications that the control group was exposed to, an important finding of the study that could have been lost if strict separation had been achieved.

While the educational component of the intervention may have been inadequate to effect a change in knowledge in the intervention group, behavior change still took place. Furthermore, while the study did not attempt to educate the physicians directly, the present approach allowed seniors to approach the family physician armed with information that could effect a change in physician action. Consequently, it is possible that participant behavior change along with physician education initiatives may have proved more effective than either one alone.

\section{Conclusion}

Osteoporosis is undertreated and patients with, or at risk of, fractures are frequently not assessed, let alone treated when appropriate. $., 8,36,37$ The participatory community development initiative reported here may have the potential to reduce the osteoporosis care gap and, importantly, be applicable to improving management of other chronic conditions. There are many clusters of older adults living in high concentrations in urban settings, and while these communities may sometimes challenge health care delivery, they are also an opportunity, appropriately developed, to manage significant health problems such as osteoporosis.

\section{Acknowledgments}

This article presents independent research funded by an unrestricted grant from the Alliance for Better Bone Health. The authors acknowledge the contributions of research assistants $\mathrm{H}$ Hanson and $\mathrm{M}$ van Zandvoort who assisted with subject recruitment and data collection. It is further acknowledged that the abstract for this paper was presented at the $31 \mathrm{st}$ Annual Meeting of the American Society for Bone and Mineral, and published online at http://onlinelibrary.wiley.com/ doi/10.1002/jbmr.565 0241305/full (abstract MO0263).

One of the authors of this paper (DAF) is supported by the National Institute for Health Research Collaboration for Leadership in Applied Health Research and Care for Yorkshire and The Humber (NIHR CLAHRC YH). The views and opinions expressed are those of the author, and not necessarily those of the National Health Service, the NIHR, or the Department of Health. CLAHRC YH would also like to acknowledge the participation and resources of partner organizations. Further details can be found at http:// clahrc-yh.nihr.ac.uk/. This trial was registered with Current Controlled Trials on September 11, 2013; registration number ISRCTN44810824.

\section{Author contributions}

MK conceived of the study, participated in the design, coordinated the conduct of the study, supervised the research assistants, participated in the data analysis and carried out revisions to the manuscript. DAF was responsible for the design, management and data analysis of the UK Telehealth intervention study, and developed and finalized this manuscript. MS directed the design of the study, contributed towards data analysis and carried out revisions to the manuscript. MYS contributed towards data analysis and provided critical revision of the paper. RGC assisted in the conception and design of the study, participated in the peer mentor's education, participated in the analysis and carried out revisions to the manuscript. All authors read and approved the final manuscript and agree to be accountable for all aspects of the work.

\section{Disclosure}

The authors report no conflicts of interest in this work.

\section{References}

1. Salkeld G, Cameron ID, Cumming RG, et al. Quality of life related to fear of falling and hip fracture in older women: a time trade off study. BMJ. 2000;320(7231):341-346.

2. Tinetti ME, Williams CS. Falls, injuries due to falls, and the risk of admission to a nursing home. $N$ Engl J Med. 1997;337(18):1279-1284. 
3. Johnell O, Kanis JA. An estimate of the worldwide prevalence, mortality and disability associated with hip fracture. Osteoporos Int. 2004; 15:897-902.

4. Elliot-Gibson V, Bogoch ER, Jamal SA, Beaton DE. Practice patterns in the diagnosis and treatment of osteoporosis after a fragility fracture: a systematic review. Osteoporos Int. 2004;15:767-778.

5. Hajcsar EE, Hawker G, Bogoch ER. Investigation and treatment of osteoporosis in patients with fragility fractures. CMAJ. 2000;1653: 819-822.

6. Metge CJ, Leslie WD, Manness LJ, et al. Postfracture care for older women. Gaps between optimal care and actual care. Can Fam Physician. 2008;54:1270-1276.

7. Solomon DH, Finkelstein JS, Katz JN, Mogun H, Avorn J. Underuse of osteoporosis medications in elderly patients with fractures. Am J Med. 2003;115:398-400.

8. Papaioannou A, Giangregorio L, Kvern B, Boulos P, Ioannidis G, Adachi JD. The osteoporosis care gap in Canada. BMC Musculoskelet Disord. 2004;5:11.

9. Barlow JH, Turner AP, Wright CC. A randomized controlled study of the Arthritis Self-Management Programme in the UK. Health Educ Res. 2000;15(6):659-663.

10. Bodenheimer T, Lorig K, Holman K, Grumbach K. Patient selfmanagement of chronic disease in primary care. JAMA. 2002;288(19): 2469-2475.

11. Sevick MA, Trauth JM, Ling BS, et al. Patients with complex chronic diseases: perspectives on supporting self-management. J Gen Intern Med. 2007;22(3):438-444.

12. Esmail R, Brazil K, Lam M. Compliance with recommendations in a geriatric outreach assessment service. Age Aging. 2000;29:353-356.

13. Mitchell JM, Kemp B. Quality of life in assisted living homes: a multidimensional analysis. J Gerontol B Psychol Sci Soc Sci. 2000; 55B:P117-P127.

14. Moroz A, Schoeb V, Fan G, Vitale K, Lee M. Convalescence care for seniors of lower Manhattan: an interdisciplinary outreach, rehabilitation, and education model. Int J Rehabil Res. 2004;27:75-78.

15. Botelho RJ, Dudrak R. Home assessment of adherence to long-term medication in the elderly. J Fam Pract. 1992;35(1):61-65.

16. Bayliss EA, Ellis JL, Steiner JF. Barriers to self-management and quality-of-life outcomes in seniors with multimorbidities. Ann Fam Med. 2007;5(5):395-402.

17. Green LW, Higgins JW. Strategies, guidelines, policies and standards: the search for direction in community health promotion. Health Promot Int. 1995;10(1):75-76.

18. Shiell A, Hawe P. Health promotion, community development and the tyranny of individualism. Health Econ. 1996;5:241-247.

19. Kloseck M, Crilly RG, Mannell RC. Involving the community elderly in the planning and provision of health services: predictors of volunteerism and leadership. Can J Aging. 2006;25(1):77-91.

20. Kloseck M, Crilly RG, Gutman G. Naturally occurring retirement communities: untapped resources to enable optimal aging at home. J Hous Elderly. 2010;24:392-412.
21. Kloseck M, Crilly RG, Misurak L. A Health Care Model for Community Seniors: A Community-Systems Approach. Report prepared at the request of the Ministry of Health and Long-Term Care. London, ON: Division of Geriatric Medicine; 2002.

22. Ho EE, Waltz J, Ramstack J, et al. Health-peers: a delivery model of health promotion among the elderly. Educ Gerontol. 1987;13:427-436.

23. Rose MA. Evaluation of a peer-education program on heart disease prevention with older adults. Public Health Nurs. 1992;9(4): $242-247$.

24. Sanders C, Seymour J, Clarke A, Gott M, Welton M. Development of a peer education program for advanced end-of-life care planning. Int $J$ Palliat Nurs. 2006;12(5):216-223.

25. Zwarenstein $M$, Treweek $S$, Gagnier JJ, et al. Improving the reporting of pragmatic trials: an extension of the CONSORT statement. BMJ. 2008;337:a2390

26. Brown JP, Josse RG; Scientific Advisory Council of the Osteoporosis Society of Canada. 2002 clinical practice guidelines for the diagnosis and management of osteoporosis in Canada. CMAJ. 2002; 167(10):S1-S36

27. Doig GS, Simpson F. Randomization and allocation concealment: a practice guide for researchers. J Crit Care. 2005;20:187-193.

28. Barlow JH, Bancroft GV, Turner A. Self-management training for people with chronic disease: a shared learning experience. J Psychol. 2005;10:863-872.

29. Coleman MT, Newton KS. Supportive self-management in patients with chronic illness. Am Fam Physician. 2005;72:1503-1510.

30. Peel NM, Warburton J. Using senior volunteers as peer educators: what is the evidence of effectiveness in falls prevention? Australas J Ageing. 2009;28(1):7-11.

31. Green LW, Kreuter M. Health Promotion Planning: An Educational and Environmental Approach. 2nd ed. Mountain View: Mayfield Publishing Company; 1991

32. Davis DA, Thomson MA, Oxman AD, Haynes RB. Evidence for the effectiveness of CME: a review of 50 randomized controlled trials. JAMA. 1992;268:1111-1117.

33. Harris D, Hiller LM, Keat N. Sustainable practice improvements: impacts of the Comprehensive Advanced Palliative Care Education (CAPCE) Program. J Palliat Care. 2007;23(4):262-272.

34. McAiney CA, Stolee P, Hillier LM, et al. Evaluation of the sustained implementation of a mental health learning initiative in long-term care. Int Psychogeriatr. 2007;19(5):842-858.

35. Bentley CL, Mountain GA, Thompson J, et al. A pilot randomised controlled trial of a Telehealth intervention in patients with chronic obstructive pulmonary disease: challenges of clinician-led data collection. Trials. 2014;15:313.

36. Giangregorio L, Papaioannou A, Cranney A, Zytaruk N, Adachi JD. Fragility fractures and the osteoporosis care gap: an international phenomenon. Semin Arthritis Rheum. 2006;35:293-305.

37. Papaioannou A, Kennedy CC, Ioannidis G, et al. The osteoporosis care gap in men with fragility fractures: the Canadian Multicentre Osteoporosis Study. Osteoporos Int. 2008;19:581-587.
Clinical Interventions in Aging

\section{Publish your work in this journal}

Clinical Interventions in Aging is an international, peer-reviewed journal focusing on evidence-based reports on the value or lack thereof of treatments intended to prevent or delay the onset of maladaptive correlates of aging in human beings. This journal is indexed on PubMed Central, MedLine,

\section{Dovepress}

CAS, Scopus and the Elsevier Bibliographic databases. The manuscript management system is completely online and includes a very quick and fair peer-review system, which is all easy to use. Visit http://www.dovepress. com/testimonials.php to read real quotes from published authors. 